\title{
Contemplación artística con personas que sufren trastorno psicótico y del estado de ánimo Aportaciones para un arteterapia receptivo
}

\author{
Lisa NIEDERREITER ${ }^{1}$ \\ lisa.niederreiter@h-da.de
}

Recibido: 23/07/12

Aceptado: 22/11/12

\section{RESUMEN}

El artículo se centra en la localización teórica del proceso receptivo artístico para personas con un trastorno psicótico o del estado de ánimo a través del discurso científico-artístico del iconic turn. Después de exponer las publicaciones existentes referentes al proceso arteterapéutico receptivo, se establece el conjunto básico de axiomas relativos al iconic turn en relación con el cambio perceptivo en estos enfermos. Surgieron importantes correspondencias entre el ser de la imagen (constancia, protección, lo contrario, extracto de realidad) y la necesidad de volver a estructurar, reorganizar y estabilizar los fenómenos de inundación en la percepción de estos enfermos, la tensión del individuo en su relación con la realidad.

Palabras clave: Arteterapia receptivo, percepción psicótica, procesos receptivos como construcción de la realidad, iconic turn

\section{Referencia normalizada}

Niederreiter, L. (2012). "Contemplación artística con personas que sufren trastorno psicótico y del estado de ánimo. Aportaciones para un arteterapia receptivo". En Arteterapia: Papeles de arteterapia y educación artística para la inclusión social Vol.7: páginas 245-260. Madrid. Servicio de publicaciones UCM.

\section{SUMARIO}

Introducción. El discurso científico-artístico centrado en el "iconic turn". Contemplación artística con personas que sufren trastornos psicóticos y del estado de ánimo. Resumen y perspectivas. Bibliografía.

\section{Art reception for people with psychiatric experiences contributions to a re- ceptive art-therapy}

\begin{abstract}
This paper analyses the theoretical foundations of art receptive procedures for people with psychotic illness on the base of the "iconic turn" discourse in recent aesthetic theory.

Fundamental axioms (such as the "surplus value" of the picture, its resemblance of reality; the role of the observer in the process of reception) are discussed in realtion to the perceptive changes that accompany psychotic illness. Important correlations are established between the nature of the picture

\footnotetext{
${ }^{1}$ Arteterapeuta. Trabaja desde hace años tratando a personas que padecen HIV y AIDS, a jóvenes drogodependientes y a adultos psicóticos. Profesora de Arte en la Universidad Ciencias Aplicadas de Darmstadt en los estudios de Trabajo Social y enseña arteterapia en la Universidad de Nürtingen. Artista plástica, se puede ver su obra en su página personal www.lisaniederreiter. Más información: homepage de la Universidad de Ciencias Aplicadas de Darmstadt www.sozarb.h-da.de (en alemán).
} 
(constancé, protective function, creation of an "other" or "opposite", reality-detail) and the necesssity to reorganise and restabilise the overpowering effects of psychotic perception in individuals and their contact to reality. The theoretical aspects are discussed with examples of practical work.

Keywords: Art Therapy receptive psychotic perception, receptive processes as construction of reality, iconic turn

\section{CONTENTS}

Introduction. The scientific-artisic discourse on the base of the "iconic turn". Art reception for people with psychiatric experiences contributions to a receptive art-therapy. Summary and perspectives. References.

\section{INTRODUCCIÓN}

Voy a comenzar este artículo con las palabras de una mujer que se vio durante décadas afectada por una depresión mayor. Debido a las graves alteraciones sufridas, tanto a nivel emocional como cognitivo, durante la fase aguda del trastorno expresó lo siguiente acerca de la contemplación de imágenes:

„Contemplar arte, interés que he descubierto gracias a la propia creación artística, ha sido hasta ahora mi última ocupación determinante posible.

A causa de que las impresiones artísticas en los libros no resplandecen ni muestran tantos matices como los colores de la naturaleza, no experimento la divergencia entre los colores que 'debería ver' y 'aquellos que verdaderamente percibo'; en este caso la belleza no produce aflicción alguna. No existe una estructura tridimensional real, de forma que necesite compensar la planicie de mi percepción. Debido a que las imágenes permanecen inertes y perduran en el tiempo, mi capacidad perceptiva, dolorosamente mermada, no me impide contemplarlos. Gracias a esto no siento, como en otras ocasiones, que las imágenes 'pasan a toda prisa'. Puedo observar los detalles todo el tiempo deseado, no 'dejo escapar' nada, no tengo la impresión general de que 'falta algo', la percepción y la compresión es completamente libre. Simplemente basta con que los ojos tanteen lentamente y con inocencia; el recorrido depende de mí. Lo asombroso es que todos las imágenes se impregnan en mi memoria, me reconfortan dándome una experiencia vital interior que aparta la soledad que siento" (Schirmeyer, 1999, 114).

Conocí a S. Schirmeyer en 1999 en la clínica psiquiátrica de Heppenheim con motivo de una exposición artística de sus propias obras.

A continuación, voy a resumir algunas funciones fundamentales de la contemplación artística para ella, tanto a nivel teórico como metodológico. S. Schirmeyer se pronuncia sobre la "inmovilidad" de la obra que le permite percibir, entender y sentir, a pesar de su abotargado estado emocional provocado por su trastorno. Incluso habla de que las imágenes la impregnan de vida a través del hecho de grabarse en su memoria.

Para poder entender el porqué de todo esto, me he centrado en el estudio de las publicaciones relacionadas con el arteterapia receptivo y el "iconic turn". Existen asombrosas correlaciones entre las investigaciones actuales de la recepción de 
imágenes y las percepción distorsionada de estas personas en relación con la contemplación artística.

\subsection{Revisión de los diferentes enfoques relacionados con el arteterapia}

A pesar de que en la práctica son muchos arteterapeutas los que sí incluyen obras de las Bellas Artes en su trabajo de diversas maneras, la bibliografía al respecto y en relación con la contemplación artística es bastante escasa.

A continuación haré una breve síntesis de las publicaciones actuales.

El enfoque más conocido es el que se creó tras H.G. Ott, un proyecto de investigación KIK (Kunst im Krankenhaus, que se traduciría como Arte en el Hospital) y posteriormente también A. Leuteritz (cf. Ziefreund, 1996), en el que se exponen cuadros en el hospital en un sentido de catarsis para el proceso curativo (cf. Bader entre otros, 1999, 99). Este método, también conocido como "iconoterapia" se basó en realizar una entrevista entre los años 1993 y 1994 a los pacientes $(\mathrm{n}=813)$ para posteriormente crear una relación de los criterios y preferencias en relación a la selección de obras de arte contemporáneas que más les ayudasen a superar su enfermedad. (cf. Meyer, 1995, p.131 y ss.)

En este mismo contexto, en el año 1976 H. Kraft realizó el primer estudio empírico acerca de cómo debe de ser "el cuadro ideal de habitación de paciente", cuyos resultados mostraron preferencia por parte de los y las pacientes de las obras postimpresionistas y puntillistas. (cf. Kraft, 1981, p.45, 1-5). En una entrevista realizada a Kraft en 1995 acerca de este tema, éste destacó que el arte, en este caso la imagen en la habitación del hospital, no cura en sí, sino gracias a estar ligado al proceso receptivo y a estar integrado en un contexto personal (Meyer, ibíd., p.156 y ss.); de este modo Kraft relativizó las ideas principales del KIK (Arte en el Hospital).

Existen pocas publicaciones sistemáticas relativas a estos procesos artísticos receptivos que presenten un enfoque terapéutico, ya que más bien suelen tratarse de artículos referidos a informes de proyectos o médicos, que pueden encontrarse parcialmente en internet. Entre los autores más importantes que se pueden encontrar está H. Petzold. Este autor nos habla de la "terapia integrativa con métodos creativos" en la que incorpora la contemplación artística (cf. Petzold, Orth, 1990). Durante una entrevista a Petzold del año 1994, éste afirmó que el objetivo principal al inicio de una terapia es conseguir desencadenar un proceso de "resonancia" en el cliente. Esto se conseguiría tanto a través narraciones sobre su niñez y adolescencia, como de un discurso centrado en sus experiencias artísticas (cf. Meyer, ibíd., 106-107).

Por tanto, lo primero será establecer un contacto terapéutico. Para Petzold resulta primordial trabajar a nivel interpersonal al hacer terapia (cf. ibíd.). A la hora de trabajar es destacable el criterio de selección de imágenes de Petzold que se basan en el "Iso-Prinzip" (se podría traducir como "principio de igual a igual"). Este principio consiste en mostrar al cliente una obra similar a su cuadro clínico; por ejemplo, en el caso de concreto de una persona que sufre una depresión no sería aconsejable mostrar una creación artística con colores chillones y estridentes (cf. ibíd.). 
Según Petzold, también hay que tener en cuenta los antecedentes vitales del cliente: "Y siempre busco los medios más afines. Por ejemplo, con personas de clase baja, que tienen gnomos decorativos en el jardín, siempre dará buen resultado el arte naif yugoslavo. En cambio, no les hablaré de Durero o Lüpertz" (ibíd., 107108). Otro aspecto fundamental para Petzold es la "capacidad de integración" de un artista a través de un cuadro (ibíd., 109). Pone el ejemplo de van Gogh que transforma su desgarro emocional a través de su arte en belleza; mediante la exposición de sus obras y la posterior visualización por parte del observador, se podrá conseguir que el segundo se identifique con el artista (cf. ibíd.).

Se menciona este efecto de la resonancia a nivel emocional en relación a la temática de la obra, Petzold se refiere a la iconografía de la virgen como un elemento apaciguador en el espectador (cf. ibíd.). Más problemática le parece la obra de Beuys y el arte contemporáneo: "Lo fundamental que busca el arte contemporáneo es provocar, es decir crear un problema. Puede funcionar desde la psicoterapia centrada en el conflicto, siempre y cuando a uno no le afecte este conflicto" (ibíd.).

G. Albertsen lleva años realizando un proyecto de terapia con pacientes con dolor en el Zentralklinikum Münster (Hospital clínico de Münster ) mediante la contemplación de imágenes bajo determinados criterio de elección, es decir, un proyecto sobre la eficacia de las imágenes (www.uni-muenster). El objetivo debe de ser un cambio y que el cliente mire más allá del dolor gracias a la provocación de las obras. Albertsen diferencia aquí entre la forma, la parte racional de la imagen y el proceso, como el aspecto emocional de la misma. (cf. Meyer, ibíd., p.111 y ss.)

\subsection{Resumen}

Los resultados obtenidos de los enfoques tratados relativos a la recepción artística, se refieren, por un lado a la necesidad de correspondencia en la temática entre los problemas de los usuarios y las imágenes seleccionadas. Esto, en cierto modo resulta muy poco preciso. Por otro lado, la mayoría de los autores promueven la integración de la contemplación artística dentro la relación terapéutica.

Estos dos aspectos se ven reforzados en una reciente publicación que he obtenido de G. Franzen relativas a la recepción artísticas en el ámbito de la rehabilitación psicológica. Franzen resalta una correspondencia significativa entre los cuadros elegidos y los conjuntos de problemas. Por ejemplo, a pacientes depresivos se les muestra La melancolía de Durero, para poder alcanzar su propia realidad mediante un proceso identificativo, y que de esta manera, vuelvan a ser personas comunicativas (cf. Franzen en Kruse, 1997, 307 y ss.). Además del impacto psicológico durante la contemplación artística, Franzen cita la necesidad de incluir la dimensión histórica, cultural y biográfica del artista en el contexto de justificación y motivos, aunque no especifique ningún detalle más al respecto.

Con el punto de vista de este autor se cumplen mis expectativas, ya que pretendo centrar mi enfoque científico en los efectos de la recepción del arte.

El debate profesional de las nuevas corrientes se ha centrado en el "iconic turn" (giro icónico) y el "pictural turn" (giro pictórico). Trata de manera interdisciplinar 
de redescubrir los significados del cuadro. Mi intención no es la de observar la recepción del cuadro desde una perspectiva aislada, como sería la percepción a nivel psicológico o a nivel simbólico, sino en su conjunto. Analizar la obra en relación al observador. Se podría decir que consiste en intentar aceptar una perspectiva antropológica más allá de los aspectos específicos como por ejemplo la simbolización.

\section{EL DISCURSO CIENTÍFICO-ARTÍSTICO CENTRADO EN EL "ICONIC TURN"}

El "iconic turn" parte de un "cambio de paradigma hacia una sociedad dominada por lo visual" (www.iconic-turn.de/index.php). Las obras pasan a tener mayor poder cultural, social y también político, lo que ocasiona tener que volver a investigar el fenómeno histórico y antropológico del cuadro (cf. ibíd.)

El "iconic turn" deriva como contracorriente del "linguistic turn" (giro lingüístico) de los años 70. Se trata de un discurso heterogéneo centrado en la historia del arte, los medios, la antropología, la psicología de la percepción y la filosofía.

En este sentido resulta complicado de delimitar; G. Boehm, uno de los principales representantes de este movimiento, habla del "retorno de las imágenes" (Boehm, 1995, 13) ubicándolo en el contexto histórico como una fuerza avasalladora de la lengua: "(...) este estatus rudimentario de la reflexión de la imagen tiene seguramente que ver con que el lenguaje en sí representa una metainstancia. También sobre las imágenes nos entendemos hablando. Bien es cierto que no queda excluida una reflexión muda, una visión estrictamente visual, como nos muestra la historia, principalmente del arte moderno, pero esta reflexión queda al margen." (cf. 326)

\subsection{El "valor añadido" de la imagen}

Quisiera comenzar con el aspecto del "valor añadido" de la imagen. A este respecto, los teóricos del "iconic turn" recurren a los representantes clásicos de la antropología y fenomenología, y como consecuencia, sus científicos, tales como M. Merleau-Ponty (cf. Halder, 2000, 206 y 141) experimentan un cierto renacimiento.

Boehm señala que una imagen supone más que una metáfora lingüística o su perífrasis lingüística, objetiva y abstraída (cf. ibíd., 27 y ss.). Esto, por ejemplo, resulta comprensible por la necesidad de una percepción sensorial por parte del espectador, es decir, la necesidad de una "mirada visual". Si se relaciona este aspecto con el concepto de "fenomenología de la percepción" de Merleau- Ponty, la mirada visual se convierte en un acto egocéntrico, ya que cada contemplación de una imagen se produce dentro del propio cuerpo del observador y se refleja.

H. Belting, de manera todavía más radical, argumenta que el sujeto es el verdadero lugar de la imagen (cf. Breidbach et al., 1999, 287). „, Sin nuestra mirada no existirían las imágenes, sino que las imágenes serían algo distinto o ni existirían. Recibimos las imágenes desde el exterior, pero las hacemos nuestras" (cf.). Esta 
"perogrullada", como él mismo la denomina, naturalmente debería diferenciar las imágenes internas de las externas lo que haría que existiese una zona gris, es decir, los recuerdos internos. Cabe destacar la importancia que da Beltings al contexto cultural (ver cf.): “A pesar de que recibimos las imágenes desde el exterior, el mundo o nuestro entorno, las convertimos en nuestra, tanto en el sentido colectivo como individual. (Belting, 2000, 7)

Las obras pictóricas son, por lo demás, más que una copia, es decir, más que una mera imitación de un objeto real (cf. Belting en Breidbach, ibíd., 34 y ss.). Las obras pictóricas, sobre todo en relación al arte contemporáneo, van mucho más allá de una imitación de la realidad, son "procesos, representaciones que no se refieren a lo existente, sino a hacerlo visible, a resaltar el 'crecimiento en el ser' (Gadamer)" (Boehm, 1995, 33). Esta perspectiva facilita que se tome conciencia de que con que cada obra pictórica posee su propia forma, su propia alma y su propia existencia.

En este contexto, Belting critica la metodología clásica de la historia del arte como una reducción a una clasificación histórica de las obras pictóricas: de este modo perderían el "propio potencial del sentido" y su "peculiar poder de representación" (cf. 35 y ss.).

\subsection{Los aspectos intrínsecos al valor añadido}

\subsubsection{Semejanza con la realidad}

El carácter central de la imagen consiste en su semejanza con un objeto real: “ La semejanza se resalta a propósito y por este motivo, esta característica es un artefacto. Un parecido natural entre dos objetos no convierte al primero en la imagen del segundo (Jonas en Boehm, 2001, 107). Esto quiere decir que, para el observador, el parecido intencionado entre el objeto en la imagen y el objeto real, y así como la manera en que este parecido está perfeccionado, hace que pueda percibir una realidad exenta de la claridad de la realidad real. En la introducción cito a una mujer que sufre un trastorno mental del estado de ánimo y que describe este aspecto como beneficioso, ya que a través de la contemplación de la imagen no se enfrenta a la discrepancia entre aquello que debería ver y lo que realmente percibe (cf. ibíd.).

El elemento central de esta semejanza reside en su estado incompleto ya que sino la imagen sería una imitación de la realidad, dejando de ser una imagen. El núcleo central de la imagen constituye por lo tanto la imitación no perfecta de la realidad. (cf. 108).

La subyacente reducción necesaria de las características del objeto reproducido que dependen del sentido de la vista genera "grados de libertad", tal y como lo denomina Jonas (cf. 109). Es decir, cuanto mejor consiga el artista representar lo real mediante el menor número de elementos característicos, mayor será la libertad de movimiento de la expresión. Continúa Jonas: "Este aspecto de lo incompleto sugiere una idealización que de ninguna manera debe encaminarse exclusivamente hacia la belleza" (cf.). 
En el arte contemporáneo, no existen límites impuestos en el manejo de esta semejanza con el mundo animado. La consecuencia, tanto para el artista como para el observador será el aumento de la imaginación, del poder imaginativo.

\subsubsection{La constancia y el simbolismo (función protectora)}

Una imagen permanece inerte y constante, aún cuando representa un acto o la atmósfera de un paisaje que en el instante siguiente se puede convertir en otro. Lo reproducido es real pero incorpóreo. Esto provoca esa tensión importante y peculiar de la obra pictórica entre realidad y virtualidad a nivel de contenido de la imagen que describe Jonas: "La semejanza puede representar lo peligroso sin dañar, lo perjudicial sin perjudicar, lo deseado sin saciar (cf. 111). O, tomando las palabras del inicio de Schirmeyer, una belleza que no produce aflicción alguna (ibíd.).

En relación con esta particular función protectora de la imagen, Kamper continúa: "Las imágenes escudan al cuerpo. El propósito es bloquear el temor al otro lado del espejo. La imagen protege del dolor. El dolor sostiene la imagen. (...) El miedo, la lesión, el dolor, quedan desterrados al otro lado cuando existe la imagen. Los cuerpos están en el exilio, al otro lado de las imágenes. Y, por el contrario, las imágenes están compuestas por sólidas lesiones debidas a un trauma aparentemente insoportable. Las ocultan: las envuelven; (...)" (Kamper en Belting, ibíd., 18).

\subsubsection{El carácter del objeto}

En última instancia, la imagen pictórica debe contemplarse desde su carácter del objeto, ya que ésta ha sido creada por un artista con un estilo, método de trabajo y pincelada propios. A su vez se trata de una imagen y en tercer lugar, evoca a la realidad que crea que se ha convertido en reproducción: "Es esta doble distinción, o esta triple estratificación, hace posible esa actualidad no causal de la imagen y apartan el azar propio de los sucesos reales" (ibíd., 113). Aquí cabe referirse a aquella cita que habla de las imágenes que permanecen inertes, que pueda tener lugar una contemplación lenta y restringida de las mismas.

\subsection{El proceso receptivo}

\subsubsection{Lo intermedio}

A continuación de esta diferenciación de todos aquellos aspectos, que, desde la perspectiva de la imagen, constituyen un aumento de valor de ésta, procederé a exponer las consecuencias del proceso receptivo, es decir, el papel que desempeña el observador.

Trataré de esbozar los cometidos del arte con las palabras de H. U. Reck: "Generalmente, es decir, independientemente de ciertas expectativas normativas en innovación, estabilización, afirmación u oposición, la confirmación o la inseguridad, el arte es un método de generación y puesta en escena de algo intermedio entre el lenguaje, la imaginación, la percepción y la acción. La percepción de la realidad no es una representación uniforme, sino a su vez su 
simulación. No existe una percepción directa o no distorsionada en la que éstas se hayan descrito de forma ontológica" (Reck en Belting et al., 2000, 187).

Con tal visión del arte, en el establecimiento de "lo intermedio" queda patente la diversidad de una amplia participación por parte del observador en la percepción de la imagen. La imagen no sirve como medio de comunicación, sino como interfaz en la confrontación entre arte, la realidad y el propio ser.

Esto quiere decir que las imágenes no tienen un sentido fijo: "El sentido no es una característica del objeto sino una figura de reflexión." (ibíd., 192), algo que en consecuencia posiciona al observador en el centro de la generación del conocimiento: "Destaca la opinión de que no existe un observador objetivo." (Reck, 1999, 241). Desde la perspectiva de la persona que ha sufrido un trastorno del estado de ánimo S. Schirmeyer también confirma lo anterior y habla del "no poder equivocarse" de la impresión general y de la absoluta libertad del propio entendimiento (cf. ibíd.).

\subsubsection{La época moderna}

El rol principal del propio observador resulta indispensable en la recepción simbólica de una obra de arte, mejor dicho, de la época moderna. Desde que las bellas artes ya no reproducen o idealizan la realidad, sino que más bien la destruyen, cuestionan, rompen y a veces abstraen por completo, el sentido se establece de diferente manera. Contemplar una obra ya no permite una confrontación con la verdad del mundo (cf. ibíd., 238).

\subsubsection{La identificación con el artista}

En este artículo cabe añadir el rol del artista que influye de manera indirecta en en el proceso receptivo del observador. Si hablamos de los paisajes de Cezanne, K. Lüdeking afirma que aunque no se trate de reproducciones naturalistas de las montañas del sur de Francia, son imágenes capaces de mostrar la apertura de las cualidades del ser, cualidades que no aspiran a un dominio de la realidad (cf. ibíd., 354), sino a comunicarse con el observador. Esto podrá aplicarse con mayor validez cuanto mayor sea la intensidad con la que el artista incluya en sus obras sus propios entornos vitales y temas biográficos (van Gogh, Toulouse-Lautrec...).

\subsubsection{El recordar}

Finalmente, cabe mencionar la función del recuerdo, de la memoria pictórica como punto de fusión entre imagen y observador, ya que en este interfaz se fusionan imagen y observador. En la memoria, como parte del sistema nervioso se almacenan las imágenes como recuerdos (cf. Belting en Breidbach, ibíd., 291). Lo percibido desde el exterior se almacena como una imagen en un lugar interno; este es el elemento central de nuestra identidad biográfica y cultural.

A través del reencuentro con las imágenes, tanto las recordadas como similares a otras ya conocidas, el observador reexperimenta sensaciones complejas de su propia biografía en parte ligadas a percepciones sensoriales. Se vuelve presente algo ya experimentado o visto. Y lo hace junto con el lugar y el momento de la vivencia. 


\subsection{Resumen}

Me resultan significativos los siguientes axiomas: se puede analizar la imagen siempre y cuando se tenga en cuenta al observador en su ser. Por otra parte, las imágenes son mucho más que meras reproducciones de la realidad, este "más" quiere decir que son más abiertas y diversas y que no sólo se reducen a clasificaciones e interpretaciones lingüísticas de "la historia del arte". Gracias a la semejanza del motivo con la realidad se experimenta una parte de la realidad, aunque al mismo tiempo, en el distanciamiento de la reproducción resulte preciso ahondar en esa parte de realidad mediante la capacidad de pensamiento y percepción.

En esta confrontación con la realidad de la imagen, al observador le ayuda el hecho de que la segunda esté disponible para él, inerte y constante en tres niveles (el primero como motivo pictórico, es decir, el extracto de la realidad, el segundo como elemento de la historia del arte, y el tercero como portador de la imagen). Su carácter objetivo reside en que incluso el extracto más brutal de la realidad se presenta de forma protegida.

La creación de "lo intermedio", dentro del proceso receptivo, permite al observador disponer del margen necesario para una confrontación con la imagen, a través del autoposicionamiento a múltiples niveles, la autoevaluación y de generar su propio sentido. Puede resultar beneficioso en este proceso que el observador adopte temporalmente el punto de vista del artista que se hace patente en la obra. Trabajar con obras recordadas facilita la apertura y consolidación de la identidad, así como la concienciación de que las imágenes son parte de nosotros, de que en nuestro cuerpo son dueñas de nuestra realidad y de nuestro bien cultural.

\section{CONTEMPLACIÓN ARTÍSTICA CON PERSONAS QUE SUFREN TRASTORNOS PSICÓTICOS Y DEL ESTADO DE ÁNIMO}

\subsection{Características de la percepción sensorial en personas que sufren trastornos psicóticos y del estado de ánimo}

Me gustaría relacionar las características de la recepción de la imagen, definidas como estéticas, con la particular percepción de la realidad de personas con trastornos mentales crónicos. Hagamos referencia a las numerosas publicaciones especializadas en relación a la distorsión de la realidad y la propiopercepción de personas psíquicamente enfermas, para poner un ejemplo: G. Benedetti las denomina "desrealización y despersonalización" (Benedetti, 1994, 67 y ss.), de forma que en el trabajo con estas personas resulta necesario promover la propiopercepción y la percepción de la realidad.

Sin profundizar demasiado en los síntomas de la distorsión perceptiva en la fase aguda del trastorno (las ideas delirantes y las distorsiones tanto cognitivas como sensoriales y emocionales), me gustaría centrarme en el aspecto de la "inundación del yo", en relación con los propios afectos y sentimientos, con el inconscientes y así como con la estimulación procedente del entorno. Los límites entre la vida interior y el mundo exterior se desdibujan, lo que imaginamos en nuestro mundo 
interno lo vivimos como la realidad y viceversa, las impresiones procedentes del exterior pueden amenazar sobremanera al Yo. R. Strobl describe esto como un "colapso de los procesos racionales del pensamiento", como una "desintegración de la forma" del campo de experiencia, que afecta a la vivencia del Yo, incluyendo el pensar, el sentir, la vitalidad y la psicomotricidad (Strobl en Thomashoff et al., 1999, 69).

Debido al consiguiente debilitamiento de las estructuras mentales, en especial de las funciones del Yo con su capacidad central de reflexión, queda patente que los afectados, la relación entre uno mismo y la realidad, entre el Yo y la realidad, sufren desde una profunda conmoción e incertidumbre hasta una completa disolución de referencias fiables. Esto se manifiesta, entre otras cosas, mediante de las enormes dificultades y miedos que muestran los afectados a la hora de establecer vínculos con los objetos (cf. Franzen, ibíd., 307).

Continuando con este razonamiento de manera lógica, es justamente la contemplación de la imagen, como ya se ha explicado anteriormente, y de una manera sumamente compleja, la que permite explorar la propia relación entre el Yo y la realidad en el espejo de la imagen.

Concretamente, esto ocurre en la confrontación con extractos de la realidad, a la hora de presentar las imágenes (por ejemplo en el caso de los paisajes franceses de Cèzanne) pero también y al mismo tiempo con la realidad del arte y sus corrientes (postimpresionismo). Se podría decir que se trata de la creación de una relación de realidad a dos niveles.

Sin embargo, ya que las imágenes no son nunca imitación de la realidad se crea aquel "añadido" de realidad, que permite al observador percibir esta realidad de manera multidimensional y amplificarla con lo propio. Volvamos a recordar una vez más la descripción de Schirmeyer en la que explica que durante la contemplación de la imagen supera la discrepancia entre aquello que ella realmente debería de ver como la realidad objetiva y aquello que ella percibe de la imagen (cf. ibíd.).

Concretamente esto significa que, a través de la contemplación de imágenes, ella puede ir acercándose a la realidad con mucha precaución sin verse confrontada desde un principio con las categorías de verdadero/falso o real/irreal, de su capacidad de percepción.

En el camino de reconstrucción del yo y la conexión con la realidad, y tras la completa disolución de percepción ordenada que ha tenido lugar durante la fase aguda del trastorno, la imagen puede proporcionar algo así como una realidad de ensayo o de ayuda, una realidad protegida. Esta teoría se puede relacionar con el supuesto de la psicología evolutiva que profesa que un trauma temprano puede ser el motivo del desarrollo ulterior de un trastorno psicótico o del estado de ánimo. Esto significa, en consecuencia, que para la reconstrucción del Yo y de la referencia a la realidad deberán ponerse a disposición medios precoces, es decir, introducidos en un área pre lingüística (cf. Thomashoff, ibíd., 155).

Aquí, se podría formular la consecuente hipótesis de que la amplificación y la distorsión de la realidad, tal y como ésta aparece en el arte contemporáneo, 
posibilita de manera extraordinaria la observación del proceso perceptivo con personas que han sufrido traumas psiquiátricos y estudiar su singularidad. Esta teoría se ve especialmente reforzada por las estrategias de ruptura consciente y distorsión de la realidad en el arte contemporáneo y su aproximación a lo subjetivo. El postimpresionismo y el expresionismo pueden jugar aquí un papel fundamental.

Ante la posibilidad de la autoreferencia en la imagen, la autolocalización en la imagen y del descubrimiento del sentido de la imagen, tiene lugar una intensa propiopercepción en un contexto real en los niveles de las sensaciones, del pensamiento, del habla y de la interacción.

A esta referencia de la realidad de las imágenes se podría atribuir asimismo el carácter de un espacio protegido: las imágenes mantienen esta localización palpable y la búsqueda de uno mismo en el otro.

Además, las imágenes en su inercia ofrecen una absoluta fiabilidad. Permanecen constantes al otro lado y protegen de esta forma la incertidumbre y la sobrecarga de la información, aspectos esenciales para la estabilización de los enfermos mentales. A esto se suma de nuevo el ya discutido simbolismo y la función protectora de la imagen; las realidades dolorosas tanto físicas como psíquicas, como por ejemplo el autorretrato de van Gogh con la oreja cortada, no son reales.

La función de las imágenes recordadas y conocidas es muy significativa, ya que dichas imágenes se viven como tesoros de lo ya se ha visto y de lo que vuelve a reconocerse, formando la identidad. Con frecuencia, los enfermos mentales crónicos se definen en función de sus déficits en concentración, rendimiento, conducta y participación social, etc. Pero gracias a la contemplación artística se sienten igual de competentes que cualquier otra persona, además de apreciados. Perciben que se toma en serio su derecho a la formación y la participación cultural.

\subsection{Evaluación definitiva del proyecto concreto}

A continuación se ilustran las hipótesis aquí propuestas mediante ejemplos de un proyecto de contemplación artística realizado con enfermos mentales crónicos. Los 5-8 participantes son pacientes de un centro de día para enfermos psíquicos en la ciudad de Darmstadt (Alemania). Hagamos un breve esquema del proyecto al completo.

\subsubsection{Esquema del proyecto}

El corte temático de estas 11 sesiones presentó una dramaturgia, en cuanto al debate planteado por el arte sobre la enfermedad mental. Lo que viene a significar que la selección artística se acercaba cada vez más al planteamiento de entender la experiencia del trastorno psicótico o del estado de ánimo.

De esta forma, las tres primeras sesiones trataron los siguientes temas: 1. el paisaje, 2. el animal en la imagen y 3. la persona en la imagen, constituyeron un acercamiento desde un entorno inanimado hacia el ser y finalmente, a través de la identificación, al ser humano. 
A su vez, en estas primeras horas se desarrolló la confianza indispensable para el trabajo pedagógicos/terapéuticos dentro del trabajo en grupal, así como el setting para las personas implicadas (participantes y dirección) y del método.

En resumen, el método consistía en la presentación de aproximadamente 15 postales con reproducciones de obras de arte de diferentes temáticas y en un inicio de diversas épocas. Se trabajaba el género en base a la información de la historia del arte referente a las obras, y el punto central lo constituía la discusión grupal entre los participantes, sus preguntas, reacciones y asociaciones de los mismos. En la segunda mitad de la sesión se reforzaba la antes citada referencia personal a cada imagen individualmente, mediante la propuesta a los diferentes participantes, de seleccionar una imagen con el fin de realizar una posterior exposición personal sobre ésta. Esta reacción tan personal hacia la obra oscilaba a diferentes niveles, tanto a nivel emotivo, cognitivo, identificativo y/o proyectivo. Las reacciones se incitaban a través de preguntas específicas, como por ejemplo: ¿Qué es lo que más le atrae y hace que se adentre en del paisaje? o ¿cuál de las personas representadas le resulta más digna de confianza? o sencillamente, ¿qué motivo le transmite en este momento la mayor sensación positiva? etc.

Las tres siguientes sesiones se centraron, a través de la concentración temática en la personalidad de un artistas (van Gogh, Kahlo, Beuys), en el debate sobre la relación entre arte y biografía, y en este contexto también en torno al sufrimiento corporal y mental. Ésta fue la parte esencial del proyecto. El cierre consistió en cuatro sesiones con temáticas seleccionadas por los y las participantes, visitas a museos y una tertulia final a modo de ritual.

Cabe destacar dentro de la selección de temas por parte de los participantes, el reiterado interés por el arte abstracto y por la historia biográfica de diferentes artistas como por ejemplo Toulouse-Lautrec.

\subsubsection{El transcurso del proyecto}

Los siguientes ejemplos son más bien ideas y reflexiones acerca de la contemplación artística con personas que han sufrido trastornos psicóticos y del estado de ánimo en el contexto del iconic turn, que se trata de una metodología probada.

En líneas generales, lo más destacado por parte de los trabajadores del centro fue la insólita capacidad de atención y de concentración de los participantes, superior a 90 minutos. Lo compararon con el lapso de concentración de unos 15 minutos característico, por ejemplo, de la terapia ocupacional. El momento de mayor importancia es el de poder encontrarse con uno mismo y simultáneamente con una realidad de confianza en las imágenes, y poder explorar la relación entre ambos aspectos.

A través del llamado valor añadido de la obra se pueden registrar y aclarar los aspectos individuales y los efectos de este múltiple proceso receptivo. El hecho de que las obras se asemejen a algo real, parcialmente, permite una recepción ligada y a su vez completamente abierta. De este modo, la participante puede expresar, al contemplar un paisaje flamenco, su anhelo de lejanía. Mientras que otra puede 
manifestar que unas montañas azules le recuerdan al mar cuando contempla un paisaje montañoso en el que predomina el color azul. Esto puede provocar una reinterpretación: las montañas azules le recuerdan al mar, por lo que definitivamente prefiere el mar a las montañas.

También, a partir de las temáticas, "animales o personas en la imagen", se hacen posibles momentos receptivos de identificación, (comentarios con respecto al cuadro de Knopff : "me encierro en mí mismo", "me gustaría ser un pájaro"), al igual que recuerdos de la infancia (como el cuadro de Macke Niña rubia con muñeca, Pisanello Hirsch) y también son posibles las reacciones proyectivas a la atmósfera del cuadro ("necesito el colorido de la tienda de sombreros de Macke para mi vida").

Con respecto a la reducida similitud del cuadro con la realidad cabe mencionar la predilección por parte de los participantes por las corrientes postimpresionista, romántica, expresionista y simbolista. Las obras pictóricas de estos estilos fueron las más escogidas, tal vez gracias a que poseen cierta semejanza con los objetos reales, ésta se reduce a lo gestual-expresivo, y el color y la forma se representan de manera subjetiva. Por otro lado, posteriormente el surrealismo se inspiró conscientemente en obras de "enfermos mentales" de la primera exposición de la colección Prinzhorn de 1921, en busca así de la cercanía a la percepción distorsionada de la realidad (cf. Gorsen en Thomashoff, ibíd.). Significativamente, las obras surrealistas radicales tuvieron una escasa aceptación. (¿Será que encierran demasiada locura, que son una confrontación demasiado fuerte con el propio sufrimiento?

En cambio durante el postimpresionismo y el expresionismo el artista tiñe, en el auténtico sentido de la palabra, la realidad de subjetividad, como por ejemplo en los cuadros del Jinete Azul y hablando psicodinámicamente, efectúa la capacidad de integración de una superposición de la realidad objetiva con la propia. Tal vez sea esto lo que experimentan los participantes del grupo de manera modélica a la hora de contemplar una obra: la superación de la división entre la realidad objetiva y la percepción subjetiva, la división que caracteriza la percepción psicótica.

Como ejemplo citaremos a Cèzanne; los participantes señalan que se puede sentir el sol de este paisaje sobre la piel y que los paisajes huelen. Esto alude a las cualidades sensoriales poliestéticas durante el proceso receptivo. También parece significativo que durante las rondas de selección nunca escogen fotografías o trabajos hiperrealistas. Parece que aquí la realidad se presenta de manera demasiado obvia y no es amplificable con sus propios recursos.

La obra como objeto histórico-artístico y como objeto propio de un estilo cumplió una función esencial a lo largo de todo el proyecto. Las preguntas giraban una y otra vez en torno a las diferencias, características y el trasfondo de las obras expresionistas, impresionistas o surrealistas; en torno al impacto del tiempo a través de su análisis histórico-social y de las humanidades, y al análisis relacionado con la historia del pensamiento, y en qué manera todo esto resulta perceptible para el observador. Esta sed cultural y educativa fue el hilo conductor de este grupo artístico. Llegados a este punto, es preciso volver a mencionar el recuerdo de la 
imagen como función perceptiva generadora de constancia y de identidad a nivel cognitivo, asociativo, simbólico y emocional. (Los participantes solían relatar en qué situaciones, también en qué museos y en qué viajes habían visto los cuadros, las imágenes sobre las que se estaba discutiendo.)

De nuevo se tornan evidentes los tres niveles de la realidad de la imagen: La imagen

1. como objeto independiente

2. como reproducción de la realidad y las connotaciones histórico-artísticas de ésta

3. como figura proyectiva e interlocutor interno

Lo poderoso que resulta "lo intermedio" originado para el proceso receptivo, es decir, que las imágenes no sirvan como mero medio de comunicación quedó patente durante las sucesivas reuniones acerca de las biografías de los artistas. Por ejemplo en el caso de van Gogh en el que los autorretratos se convirtieron en el foco de mayor interés, destacan los intentos palpables de los participantes por comprender las cualidades emocionales ("sostenerse, descubrirse, realmente no estar ahí"). Y siempre estuvo presente la vulnerabilidad psíquica de van Gogh, su estancia en la institución, - y de alguien que ha padecido algo similar. Con el autorretrato del artista con la oreja cortada se pudo reconocer esto, pero sólo se verbalizó y se instrumentalizó limitadamente al hacer referencia a la enfermedad mental. La pregunta acerca de si uno podía aprender de van Gogh a lidiar con su propia locura quedaba demasiado lejana, o quizás demasiado cercana.

La experiencia durante la quinta sesión acerca de la vida y obra de Kahlo resultó similar. Se podía hablar sobre el peligro de las historias de amor como salvación del alma, pero en general el sufrimiento representado era demasiado directo. Fue entonces cuando se formuló la necesidad de obras con bonitos paisajes y surgieron los comentarios tanto defensivos como jocosos acerca de un dramático autorretrato de Kahlo con el pelo corto en el que renegaba de su amor por Diego Rivera: “¿No vamos todas las mujeres a la peluquería cuando queremos que nuestra vida mejore?" comentó una de las participantes.

Volvamos a la función de la imagen que por un lado confronta y por el otro protege. A continuación algunos ejemplos extraídos de la sexta sesión acerca de Beuys, cuyo arte frágil, difícil y provocativo sin duda representó el mayor desafío para el grupo. También aquí se pudieron abordar aspectos de la enfermedad. Una participante relacionó la obra Schafsskelett (Esqueleto de oveja) con su distorsión perceptiva aguda al contemplar el color blanco. Otra participante manifestó acerca de la obra Zwei weisse Kreuze auf Rot (Dos cruces blancas sobre rojo) que el curarse es esencial, pero que las medicina naturista no era para ella y que prefería la medicina clásica. A través de esta declaración expresó su actitud positiva hacia los psicofármacos.

No fue hasta la sesión de Toulouse-Lautrec cuando se estableció la relación entre enfermedad y capacidad artística. Con asombro se reconoció la enfermedad entre los artistas y la dimensión más humana de la persona admirada. Causó un gran interés su manejo de la soledad y naturalmente la ciudad de París. 
Los trabajadores de la institución también resaltaron, además del prolongado periodo de concentración, el gran interés de los participantes por los demás participantes y la diligente interacción entre los miembros del grupo. Durante la segunda sesión reaccionaron con preocupación cuando una de las participantes abandonó la sala. Algunos preguntaron alarmados si se habían propasado con los comentarios acerca del cuadro seleccionado. Por lo general, en la rutina del centro de día las conversaciones personales y las referencias a los demás compañeros resultan bastante excepcionales. Con respecto a esto pueden ponerse de manifiesto dos aspectos: las imágenes proporcionan recursos especiales en la superposición de la realidad interna con la externa, y por otro lado, pueden encontrarse con el otro como una persona de manera nueva y diferente, pero sin tener que negar su enfermedad.

\section{RESUMEN Y PERSPECTIVAS}

Las perspectivas concluyentes de este proyecto podrían ser una continuación de la exploración del potencial de la imagen en su esencia para personas que han sufrido trastornos psicóticos y del estado de ánimo, sobre todo en la zona de conflicto entre la percepción de uno mismo y la percepción de la realidad. La percepción de la imagen se convierte, debido al discurso acerca del iconic turn, en un terreno para la construcción y localización de la realidad personal inducida, es decir, algo que la persona afectada había perdido. A través de la contemplación de la imagen se puede volver a disponer de la realidad sin restricciones.

Otro resultado del proyecto sería una posible sistematización de la selección de las imágenes y un método en función del grupo. Aquí el peligro radicaría en ajustar la imagen a la hora de fijar las metas terapéuticas.

También me parece significativa la perspectiva por parte de los participantes de negar las posiciones artísticas que imitan la locura sin censura y el art brut (CoBrA y parte del surrealismo). A las personas que han sufrido trastornos psicóticos y del estado de ánimo les pueden provocar cierto rechazo los artistas que juegan con la ausencia de límites entre realidad y el mundo propio, que caracteriza a las personas con trastornos psicóticos y del estado de ánimo.

Al unificar este proyecto clínico con la perspectiva artística del iconic turn camino hacia una metolodología del arteterapia receptivo, en primer lugar puede extraerse una conclusión positiva en relación a un profundo análisis substancial de la contemplación artística para la construcción de la realidad de uno mismo.

Esto, es tanto más efectivo con grupos de clientes que sufren trastornos psicóticos o del estado de ánimo y que en tienen que combatir especialmente la problemática de una percepción de la realidad distorsionada o incluso imposible. El arte $\mathrm{y}$ en especial el arte contemporáneo, gracias a sus estrategias de cuestionamiento, expansión y subjetivización, representa recursos fiables, robustos y de gran alcance para el proceso de recepción y evaluación arriba citados. 


\section{REFERENCIAS BIBLIOGRÁFICAS}

BADER R, BAUKUS P, MAYER-BRENENSTUHL A (Hrsg., 1999). Kunst und Therapie. Nürtingen

BELTING, KAMPER (Hrsg., 2000). Der zweite Blick. München

BENEDETTI G (1994). Todeslandschaften der Seele. Göttingen

BOEHM G (Hrsg., 1994). Was ist ein Bild? München

BREIDBACH O, KLAUSBERG K (Hrsg., 1999) VIDEO ERGO SUM. Hamburg

KRAFT H (1981). Das geeignete Krankenzimmerbild; In: Deutsches Ärzteblatt; $1981 / 45$

KRUSE O (Hrsg., 1997). Kreativität als Ressource für Veränderung und Wachstum. Bonn

MEYER U (1995). Der andere Blick, von der Kunsttherapie zur Ikonotherapie. Diplomarbeit der BUGH Wuppertal, Prof. Bazon Brock.

RECK H.U. (2003). Kunst als Medientheorie. München

SCHIRMEYER S. (1999). Schwarze Bilder Schöne Bilder Skulpturen. Heidelberg THOMASHOFF H-O,NABER D(Hrsg., 1999). Psyche und Kunst. Stuttgart, New York

ZIEFREUND W (1996). Therapien im Zusammenspiel der Künste. Tübingen 